\title{
Competências em foco: Extensionista Rural, uma profissão de multifuncionalidades
}

\author{
Competences in focus: Rural Extensionist, a multifunctionality profession \\ Competencias en foco: Extensionista Rural, una profesión multifuncional
}

Recebido: 26/04/2021 | Revisado: 19/05/2021 | Aceito: 22/05/2021 | Publicado: 08/06/2021

\author{
Nathalie Abreu Fidelis da Silva \\ ORCID: https://orcid.org/0000-0002-4226-1503 \\ Universidade Federal de Viçosa, Brasil \\ E-mail: nathalie.silva@ufv.br \\ Nathália Thaís Cosmo da Silva \\ ORCID: https://orcid.org/0000-0001-6630-796X \\ Universidade Federal de Viçosa, Brasil \\ E-mail: nathaliacosmo@ufv.br \\ Marcelo Leles Romarco de Oliveira \\ ORCID: https://orcid.org/0000-0003-2746-8407 \\ Universidade Federal de Viçosa, Brasil \\ E-mail: marcelo.romarco@ufv.br
}

\begin{abstract}
Resumo
A literatura apresenta inúmeros trabalhos que discorrem sobre as diversas atribuições e possíveis formações dos agentes de extensão rural. Buscou-se com o presente trabalho esclarecer as demandas das atuais atribuições elencadas no bojo profissional do extensionista rural, e responder quais são as competências atuais postuladas aos profissionais de Extensão Rural. A opção metodológica escolhida foi a revisão bibliográfica narrativa que envolve o tema e dialoga com a problemática apontada, analisando teses, dissertações e artigos científicos. Todo material foi lido em sua íntegra, categorizados e analisados criticamente. Lançou-se luz sobre a trajetória histórica da Extensão Rural e suas implicações no comportamento dos agentes extensionistas e buscou-se compreender as demandas institucionalizadas no exercício de suas funções. Como resultado deste trabalho, foi possível perceber que a multifuncionalidade é uma característica inerente à profissão de extensionista rural. Enquanto agente de implementação de políticas públicas, a teoria que define burocratas de nível de rua permitiu vislumbrar a importância da atuação do agente de extensão rural na execução de programas governamentais. Ainda que os profissionais de Extensão Rural se orientassem apenas por normativas, a realidade do campo em um Brasil tão diversificado e dinâmico, não permite exigir tamanha multifuncionalidade deste profissional, sendo necessária a formação de equipes multidisciplinares, uma vez que a contribuição de um agente extensionista pode ser complementada pela formação do outro. Sobre as novas condições frente à crise sanitária mundial, uma ATER remota faz emergir um novo portfólio de competências, sendo mister que estudos futuros também abordem avaliações sobre essas competências.
\end{abstract}

Palavras-chave: Competência; Multidisciplinaridade; Extensão rural.

\begin{abstract}
The literature presents countless works that talk about diverse attributions and possible training of rural extension agents. The present work sought to clarify the demands of the current attributions listed in the extensionists, and to answer what are the current updates postulated to the professionals of Rural Extension. The methodological option chosen was a bibliographic narrative review that involves the theme and dialogues with a pointed problem, analyzing theses, dissertations and scientific articles. All material was read, categorized and critically analyzed. This document helps to explain the historical trajectory of Rural Extension and its conclusions on the behavior of extension agents and sought to understand how institutionalized demands in the exercise of their functions. As a result, was possible have a perception that multifunctionality is a characteristic inherent to the profession of extensionists. As an agent for the implementation of public politics, the theory that defines street-level bureaucrats glimpses the importance of the rural agent executing government programs. Even though Rural Extension professionals were guided only by regulations, the reality of the field in such a diverse and dynamic Brazil, does not allow demanding such multifunctionality from this professional, fact that requires the formation of multidisciplinary teams, since the contribution of an extension agent it can be complemented by the training of other. Regarding the new conditions in face of the global health crisis, a remote ATER gives rise to a new portfolio of skills, and it is necessary that future studies also address evaluations on these competencies.
\end{abstract}

Keywords: Competence; Multidisciplinary; Rural extension. 


\begin{abstract}
Resumen
La literatura presenta innumerables trabajos que hablan sobre diversas atribuciones y la posible formación de los agentes de extensión rural. El presente trabajo buscó aclarar las demandas de las atribuciones actuales enumeradas en la extensión profesional del extensionista rural, y dar respuesta a cuáles son las competencias actuales postuladas a los profesionales de Extensión Rural. La opción metodológica elegida fue la revisión bibliográfica narrativa que involucra el tema y dialoga con el problema señalado, analizando tesis, disertaciones y artículos científicos. Todo el material fue leído en su totalidad, categorizado y analizado críticamente. Se arrojó luz sobre la trayectoria histórica de Extensión Rural y sus implicaciones para el comportamiento de los extensionistas y se intentó comprender las demandas institucionalizadas en el ejercicio de sus funciones. Como resultado, fue posible tener la percepción de que la multifuncionalidad es una característica inherente a la profesión de extensionista. Como agente de implementación de políticas públicas, la teoría que define a los burócratas de calle permitió vislumbrar la importancia del rol del extensionista rural en la ejecución de los programas de gobierno. A pesar de que los profesionales de Extensión Rural se guiaron solo por regulaciones, la realidad del campo en un Brasil tan diverso y dinámico, no permite exigir tal multifuncionalidad a este profesional, requiriendo la formación de equipos multidisciplinarios, ya que el aporte de un extensionista se puede complementar con la formación del otro. En respecto a las nuevas condiciones ante la crisis sanitaria mundial, un ATER remoto da lugar a un nuevo portafolio de habilidades, y es necesario que los estudios futuros también aborden las evaluaciones de estas habilidades.
\end{abstract}

Palabras clave: Competencia; Multidisciplinariedad; Extensión rural.

\title{
1. Introdução
}

Há muito se discute sobre as competências assumidas pelos profissionais que se dedicam à Extensão Rural. A literatura apresenta inúmeros trabalhos que discorrem sobre as suas diversas atribuições e possíveis formações destes profissionais, Paulo Freire (1983), Kreutz et. al. (2005), Peixoto (2008), Ramos e Caporal (2011), Rocha Junior e Cabral (2016), são apenas alguns autores que tocam nesse tema em diferentes estágios. Em um contexto histórico de constantes transformações, as competências atribuídas aos profissionais que se dedicam à Extensão Rural sofreram diversas mudanças.

A partir de sua institucionalização nacional, há mais de 60 anos, a atuação de extensionistas rurais vem fazendo parte de um debate contínuo (Peixoto, 2008). Um marco de referência dessas discussões foi a construção da PNATER - Política Nacional de Assistência Técnica e Extensão Rural, sobre ela Caporal afirma que ao longo do ano de 2003, houve intensa discussão com mais de 100 entidades em um processo democrático e participativo, o que conferiu alta legitimidade sóciopolítica para a construção da PNATER (Caporal, 2006). Para Zarnott et al. (2015), essa política prometia um atendimento voltado para o desenvolvimento sustentável, para a agroecologia, para a valorização da diversidade cultural e produtiva das famílias agricultoras, sendo reconhecida como uma vitória entre os que pautavam uma atuação crítica e singular da Extensão Rural. Contudo, algumas modificações foram feitas no corpo do texto da lei antes de ser aprovada, sendo sancionada uma Lei de Assistência Técnica e Extensão Rural (Ater), em 2010, com uma redação com foco na produção, e que abriu margem para o retorno ao velho modelo de Extensão Rural difusionista e produtivista (Caporal, 2011).

Confirmando essa lacuna, Zarnott et. al. afirmam que setores que antes não disputavam a Extensão Rural, como a CNA (Confederação Nacional da Agricultura e Pecuária do Brasil), passaram a fazê-lo e em seguida, no final de 2013 o Governo Federal anunciou a criação da Agência Nacional de Assistência Técnica e Extensão Rural (ANATER). Esta última, em contraposição a PNATER, recolocou como orientação geral para o serviço de Extensão Rural o difusionismo tecnológico (Zarnott et. al, 2015).

Nesse contexto, tanto a normatização da PNATER, onde consta: "adoção dos princípios da agricultura de base ecológica como enfoque preferencial para o desenvolvimento de sistemas de produção sustentáveis" (Lei n 12.188 , de 11 de janeiro de 2010), quanto outros órgãos internacionais de referência, a exemplo da FAO (Food and Agriculture Organization Organização das Nações Unidas para Alimentação e Agricultura) - que apoia e divulga em sua página oficial documentos desenvolvidos pelo extinto MDA (Ministério de Desenvolvimento Agrário), tais como o "Caderno de Boas Práticas de Ater" criaram expectativas com relação às demandas de uma ação extensionista e de assessoramento que estimulasse e apoiasse um desenvolvimento rural mais sustentável e que visassem a melhoria da qualidade de vida do público rural. Esse é um anseio que 
foi alvo de trabalho do GFRAS (Fórum Global para os Serviços de Assessoria Rural) e também de várias Conferências Nacionais sobre Assistência Técnica e Extensão Rural, que será discutido mais profundamente na seção 3.

Partindo desse contexto histórico, em que o profissional de Extensão Rural sofre diversas transformações quanto a sua atuação, do difusionismo à abordagem participativa, traçou-se a orientação deste artigo, cujos autores objetivaram esclarecer as demandas das atuais atribuições elencadas no bojo profissional do extensionista rural, e responder a seguinte questão: Quais são as competências atuais postuladas aos profissionais de Extensão Rural por serem perseguidas pelas agências de Ater e referenciadas por órgãos internacionais de extensão e pelos estudos acadêmicos?

Estruturou-se o presente artigo em cinco seções: a introdução que se lê no momento, em seguida, um tópico metodológico, logo após, uma panorâmica histórica que convida o leitor a explorar o contexto de origem do profissional no Brasil e perceber a trajetória das transformações que se fizeram presentes até os tempos atuais, adiante, uma exposição sobre as competências que se delegou ao extensionista segundo o seu contexto histórico e profissional, e finaliza com reflexões dos autores.

\section{Metodologia}

Como recurso metodológico optou-se por utilizar a revisão bibliográfica narrativa que envolve o tema e dialoga com a problemática apontada, analisando teses, dissertações e artigos científicos. Conforme defendido por Rother (2007), artigos de revisão narrativa são oportunas para descrever e debater o "estado da arte" de um determinado assunto, sob ponto de vista teórico ou contextual. Como limitação do método podemos apontar a impossibilidade de reprodução do processo, não obstante, as revisões narrativas podem contribuir no debate de determinadas temáticas, pois a partir da interpretação e análise crítica do autor é possível levantar novas questões permitindo colaborar na aquisição e atualização do conhecimento em um curto espaço de tempo (Rother, 2007). Segundo Carnwell (2001), uma boa revisão não é apenas resumir a literatura, mas discutir criticamente, identificar problemas metodológicos, e apontar lacunas de pesquisa. Como categorias analíticas utilizou-se os autores Fleury e Fleury (2001) e Sulaiman e Davis (2012) para o conceito de competências e capacidades, e ainda o autor Lipsky (2019) para inserir o contexto de burocratas a nível de rua.

Desta forma, considerando o objeto do estudo, os artigos referentes à temática abordada foram pesquisados no banco de dados das bibliotecas eletrônicas SciELO, Periódicos da CAPES, Biblioteca do Instituto Brasileiro de Informação em Ciências e Tecnologia, Google Acadêmico e ScienceResearch, no período de junho de 2019 a abril de 2021. Para esse fim, utilizou-se os seguintes descritores: Extensão Rural, capacidades do extensionista rural, competências do extensionista rural, histórico do profissional de extensão e suas variantes. Ao banco de dados incorporou-se materiais indicados por professores que atuam na mesma temática. Por resultado, estes materiais foram lidos em sua íntegra, categorizados e analisados criticamente.

\section{Resultados e Discussão}

\subsection{Contextualização Histórica}

Para compreender as transformações da atuação do extensionista no campo é necessário explorar a trajetória histórica da Extensão Rural no Brasil a fim de melhor compreender elementos do momento presente. Sendo assim, nesse capítulo far-seá um breve passeio pela linha do tempo até os dias atuais. Abaixo, apresentamos a Figura 1, em que serão apontados os prinscipais pontos apresentados no artigo: 
Figura 1. Linha do tempo da institucionalização Extensão Rural no Brasil.

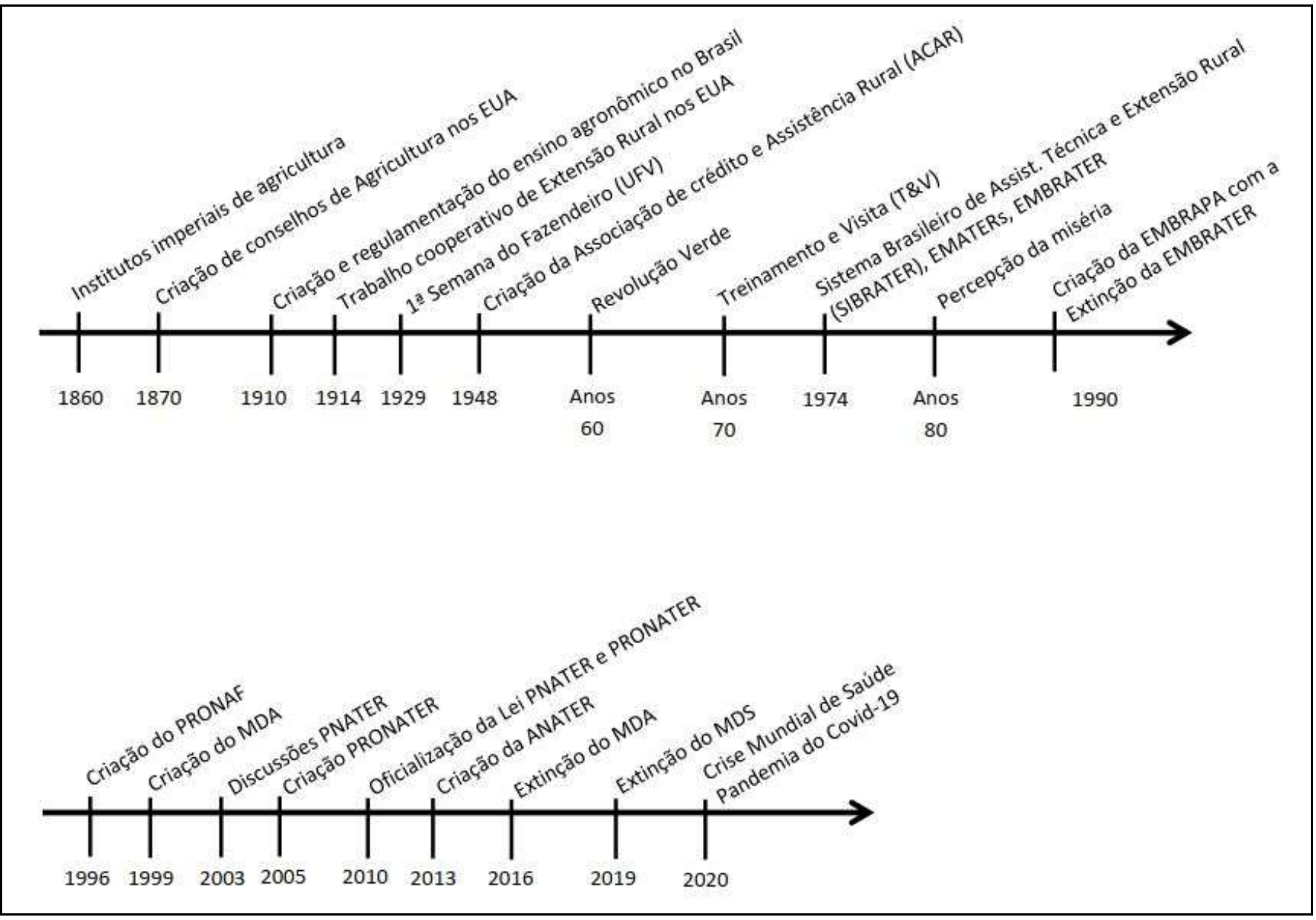

Fonte: Elaborada pelos autores com base nos artigos da revisão bibliográfica.

A partir de um estudo sobre a evolução da legislação brasileira, em uma investigação feita por Peixoto (2008), o autor afirma que o governo federal propunha ações de Extensão Rural, não obstante rudimentares, e cita como exemplo quatro institutos imperiais de agricultura, que foram instalados nos estados da Bahia, Pernambuco, Sergipe e Rio de Janeiro. Criados em 1859 e 1860, detinham atribuições de pesquisa, ensino agropecuário e de difusão de informações (Peixoto, 2008).

Já para Fonseca, a maior influência das práticas extensionistas tem suas raízes nos Estados Unidos da América do Norte, após a Guerra de Secessão (Fonseca, 1985, p.37), quando a agricultura americana atravessou um processo de reestruturação de seu modelo escravista para o mercantil e capitalista. A autora afirma que os fazendeiros americanos se organizaram em associações agrícolas com o propósito de resolver problemas de produção e comercialização. Por meio da criação de Conselhos de Agricultura, por volta de 1870, agricultores organizados promoviam conferências e cursos de curta duração, e realizaram parcerias junto a instituições de ensino e pesquisa, criando diversos Colégios de Agricultura e estações experimentais dentro do campo (Fonseca, 1985, p.37).

Aqui no Brasil, as iniciativas para fomentar a formação de profissionais iniciaram em 1910, Peixoto (2008) afirma que em um decreto sancionado pelo presidente Nilo Peçanha - com nada menos que 591 artigos - criou e regulamentou o Ensino Agronômico em seus níveis básico, médio e superior, atendendo também à agricultura e às indústrias correlatas, assim, englobavam o ensino agrícola, de medicina veterinária, zootecnia e indústrias rurais.

Enquanto isso, a extensão americana vinha funcionando como elo entre as populações rurais e as estações de pesquisa experimentais, juntamente com as instituições universitárias (Fonseca, 1985, p.39). 
De acordo com essa mesma autora:

"Em 1914, o Governo Federal encapou todas essas experiências anteriores, instituindo e oficializando o Trabalho Cooperativo de Extensão Rural, cuja finalidade era veicular, entre a população rural americana ausente dos Colégios Agrícolas, conhecimentos úteis e práticos relacionados à agricultura, pecuária e economia doméstica, para a adoção de modos mais eficientes na administração da propriedade rural e do lar." (Fonseca, 1985, p.39).

A "importação" da metodologia educacional praticada nos Estados Unidos, realizada pelo serviço de Extensão Rural americano (Agricultural Extension Service) foi ideia do professor norte-americano Peter Henry Rolfs. Esta foi uma decisão do então presidente da República Arthur Bernardes, que desejava beneficiar sua terra natal fundando, em 1926, a Escola Superior de Agricultura e Veterinária de Viçosa (ESAV - atual Universidade Federal de Viçosa), em Minas Gerais (Olinger, 2020). Destaca-se ainda, a Semana do Fazendeiro, um evento pioneiro de ações extensionistas, que aconteceu pela primeira vez em 1929, e que segundo Olinger (2020, p.29), "naquela "Semana" os professores e instrutores realizavam palestras educativas, demonstrações de métodos, dias de campo sobre modernas práticas de agricultura, pecuária, silvicultura, conservação do solo, irrigação, economia doméstica e outros assuntos de interesse das famílias rurais mineiras".

Fazendo um parênteses contextual, podemos inferir que no período pós-Segunda Grande Guerra, houve uma grande preocupação com a fome nos países "subdesenvolvidos", e ainda havia o discurso de que esse era um resultado do déficit de produção de alimentos no mundo, assim, esses modelos americanos foram tomados como exemplo para permitir o "desenvolvimento" do meio rural. Uma crítica necessária está no argumento do sociólogo Stavenhagen que conceitua "Desenvolvimento" como: mudança, evolução, crescimento, metamorfose. E provoca:

"[...] desenvolvimento de onde para onde, e de quê para quê?; de pequeno a grande?; de atrasado a adiantado?; de simples a complexo?; de jovem a velho?; de estático a dinâmico?; de tradicional a moderno?; de pobre a rico?; de inferior a superior?" (Stavenhagen, 1985, p.12).

Mas, por que as populações rurais dos países latinos eram vistas como local do atraso tecnológico com acentuado estado de pobreza? Stavenhagen (1985) explica que, do início dos anos 50 até fins dos anos 70, predominou-se uma concepção linear evolucionista de pensar o desenvolvimento. Reconhecia-se internacionalmente que algumas regiões do mundo (geralmente colônias ou ex-colônias das potências européias) eram "atrasadas" econômica, social, cultural e, até mesmo politicamente. Assim, eram classificadas mediante indicadores que reportavam ao atraso, como baixos padrões de vida para boa parcela da população, acentuada pobreza, fome, baixa renda per capta e reduzido Produto Interno Bruto. Assim, para este autor, os valores foram definidos antes mesmo de se discutir com a população o que se queria adotar como planejamento de desenvolvimento, pois as premissas básicas de cientistas sociais ou planejadores (entende-se governantes) as premissas básicas de valor já haviam sido adotadas, portanto, a solução para o atraso era: o crescimento econômico (Stavenhagen, 1985).

Neste sentido, Rodolfo Stavenhagen (1985, p.13-14) conclui:

"O modelo segundo o qual se esperava que os países subdesenvolvidos encontrassem seu próprio futuro vinha do mundo industrializado. O progresso através da escala de desenvolvimento era medido, julgado e avaliado por uma nova casta de especialistas Internacionais. Os países eram classificados numa hierarquia de acordo com seu desempenho, como atletas numa pista, orientando a distribuição ou suspensão dos recursos das agências Internacionais de financiamento e ajuda. Em parceria com agências de extensão americanas, e utilizando o modelo clássico de transferência de tecnologia [grifo nosso], foram implantadas diversas ações pelos governos dos países latino-americanos."

Além da questão dos critérios desenvolvimentistas predominantes no pensamento daquela ocasião, é possível abranger à justificativa do discurso do projeto Revolução Verde, implantado no Brasil a partir da década de 1960 e que 
prometia acabar com a fome mundial. Seu objetivo era a difusão da produção agrícola moderna que fazia uso de máquinas, sementes mais resistentes melhoradas geneticamente, e ainda utilizando-se de adubos químicos e agrotóxicos. Sobre esse tema, Lazzari e Souza (2017, p.3) afirmam que o uso de implementos agrícolas e produtos químicos na lavoura se iniciou pósSegunda Guerra Mundial (1939-1945), uma vez que as indústrias químicas precisavam escoar os produtos desenvolvidos, pois tendo a guerra findada era necessário buscar novos mercados que consumissem as descobertas feitas pelo segmento.

Feitas as ressalvas para a compreensão do momento histórico, é possível compreender o contexto em que se deu o processo de implantação dos serviços de ATER no Brasil, que, segundo Peixoto (2008, p.17) ocorreu nas décadas de 1950 e 1960, com a criação de Associações de Crédito e Assistência Rural (ACAR) nos estados, as quais, posteriormente foram todas coordenadas pela Associação Brasileira de Crédito e Assistência Rural (ABCAR). Sobre o início desse processo, Olinger (2020, p.33) menciona que, no ano de 1948, Nelson Rockefeller, membro de uma das famílias mais ricas dos Estados Unidos da América, conhecida como os Rockefeller, chegou ao Brasil. Considerado um filantropo, foi sócio fundador da Associação Internacional Americana (American International Association), destinada a ajudar no desenvolvimento econômico e social da América Latina. Esteve em São Paulo e em seguida em Minas Gerais a ofrecer apoio a título de filantropia, quando se interpretava este apoio como missão de interesse do governo norteamericano. Tendo o governador de São Paulo recusado a proposta, por não concordar com os termos da cooperação (o que significava a escolha e nomeação de dirigentes escolhidos e aconselhados por americanos), o governador de Minas Gerais, Milton Campos, não se opôs àquela exigência. Sobre esse fato, Olinger (2020, p.33) pontua:

"Era novembro de 1948 e nascia a Associação de Crédito e Assistência Rural, a Acar, uma associação civil, sem fins lucrativos, de direito privado, incumbida de fundar e executar um Serviço de Extensão Rural, destinado a "elevar o nível de vida das famílias rurais mineiras". Baseado na assistência técnica, econômica e social, mediante o uso de processos de ensino-educação [grifo nosso], constantes na metodologia clássica do Extension Service norte-americano $[\ldots] "$

Basicamente funcionava da seguinte forma: os EUA emprestavam recursos financeiros a juros baixos aos governos parceiros, que abriam agências de crédito privado para proprietários rurais e por meio de uma equipe técnica levavam instruções aos agricultores sobre como aplicar os métodos americanos de produção agrícola. É interessante ressaltar que os cientistas eram considerados os "possuidores do saber", ao agricultor local não cabia questionar e sim aplicar o "conhecimento difundido".

Mas como se dava esse processo de ensino-educação? O método conhecido como difusionista, foi um modelo clássico educacional de transferência de tecnologia defendido por Everett M. Rogers, em que se pregava a comunicação em um só sentido, cujo objetivo era passar a informação persuadindo o interlocutor a adotar a técnica apresentada. Este formato foi adotado a partir do modelo norteamericano e predominou nos serviços de Extensão Rural do Brasil durante os anos 1960, período vigente do programa Revolução Verde, já mencionado. Sobre esse período Fonseca (1985, p.41) aponta que "foi característico dessa primeira fase um exagerado entusiasmo fundado na ideia de que era necessário informar e persuadir os agricultores a adotarem melhores práticas de produção de fibras e alimentos [grifo da autora]".

Adiantando a linha do tempo para os anos 1970, conforme observado por Axinn (1988), as características principais da extensão à época incluíam a abordagem do Desenvolvimento Rural Integrado (DRI), o surgimento do sistema de Treinamento e Visita (T\&V) e a substituição do modelo de difusão de inovações pelo de oferta de pacotes de serviços que integram a Extensão Rural com a pesquisa agrícola e o crédito rural. A técnica reconhecida como T\&V surgiu como método em 1977, desenvolvido pelo Banco Mundial para ser implementado nos continentes africano e asiático. No Brasil, uma parceria entre Embrapa, IAPAR, EMATER-PR, cooperativas e empresas privadas adaptaram o $\mathrm{T} \& \mathrm{~V}$ para a realidade brasileira. Assim, o foco era a transferência e a validação dos conhecimentos e tecnologias indicadas para as culturas de soja, 
milho e trigo, inicialmente no Paraná. Mais tarde incluíram-se as culturas do algodão e do feijão (Domit, Lima, Adegas, Dalbosco, Oliveira \& Campanini, 2007). Na década de 70 toda inovação tecnológica advinda da produção agrossilvipastoril eram derivadas de instituições públicas federais que formavam várias estações experimentais em diversos Estados e que eram coordenadas pelos chamados IPEAs - Institutos de Pesquisa Agropecuária (Olinger, p.53. 2020).

A partir dessa década houve interesse do governo brasileiro em promover e garantir a articulação entre todas as ações da Ater e de pesquisa agropecuária, assim, foi sancionado em dezembro de 1972, pelo Presidente da República Emílio Garrastazu Médici, a Lei n 5851, que autorizava o Poder Executivo a instituir a Empresa Brasileira de Pesquisa Agropecuária - Embrapa (Olinger, 2020). Dois anos depois, em 1974, através da Lei nº 6.126, institui-se a Empresa Brasileira de Assistência Técnica e Extensão Rural (EMBRATER), empresa pública, vinculada ao Ministério da Agricultura, com personalidade jurídica de direito privado e patrimônio próprio (Peixoto, 2008).

Todavia, permaneciam altos os índices de miséria da população nos países em desenvolvimento, e se intensificaram os debates sobre a fome no mundo. Sobre a questão da fome, Elisabete Maniglia (2009, p.24) comenta que "com o aumento da produção de alimentos, nos fins da década de 1970, o mundo despertou para a realidade e passou a encarar a situação da fome e desnutrição como um problema realmente de acesso e não de produção".

Para ilustrar a situação brasileira na década de 1980, apresenta-se a seguir a transcrição de parte de uma notícia publicada no Jornal Folha de São Paulo, em 9 de abril de 1986, com o título "77 milhões passam fome", e subtítulo "Sarney recebe do sociólogo Hélio Jaguaribe um plano para combater a miséria no país":

"O sociólogo Hélio Jaguaribe, 62, entregou ontem ao presidente José Sarney um plano de metas até o ano 2000, com o qual o governo pretende combater a fome e a miséria absoluta que afetam $60 \%$ dos brasileiros - 76,9 milhões de pessoas, segundo dados de 1984 do IBGE (Fundação Instituto Brasileiro de Geografia e Estatística). O estudo foi encomendado em agosto do ano passado e servirá de base para a implantação de programas sociais, como a distribuição de alimentos à população de baixa renda. $\mathrm{O}$ presidente comentou durante o encontro que está "irreversivelmente dedicado ao esforço de modificar a sociedade, para torná-la mais equitativa e mais humana", disse Jaguaribe à Folha." (Jornal Folha de São Paulo, 1986).

Na perspectiva do meio rural, muito se questionou sobre a eficácia das metodologias difusionistas, não obstante os esforços políticos de levar progresso ao campo permitissem avanços no aumento da produção, as desigualdades permaneciam, pior, acentuavam-se, pois a tecnologia favorecia apenas àqueles que possuíam grandes frações de terra e recursos financeiros para comprar os chamados "pacotes tecnológicos". Sobre este termo, conceitua-se que tecnologia são como um pacote de informações organizadas, de diferentes tipos - sejam elas científicas ou empíricas - oriundas de várias fontes (descobertas científicas, patentes, livros, manuais, desenhos, etc...) obtidas através de métodos de pesquisa e desenvolvimento, e que é utilizado para a produção de bens e serviços (Sabato \& Mackenzie, 1981). Portanto, como pacote tecnológico no meio rual, entende-se aqui como técnicas em formato de receituário, com um passo-a-passo oferecido por empresas, em sua maioria multinacionais, que indicam instrumentos e maquinários específicos a se utilizar, aditivos químicos (adubos ou agrotóxicos), sementes clonadas e etc.

Nesse contexto, um dos principais críticos das metodologias rogerianas difusionista, na dácada de 1980, foi o educador e filósofo Paulo Freire, que em seu livro "Extensão ou Comunicação", rebateu tais métodos educacionais e denunciou as condições de aprendizagem que os extensionistas impunham à população do campo, transformados em objetos, refutava em seu texto as diferenças entre educar, domesticar e libertar. Freire acreditava que as práticas difusionistas, por si só, negavam os indivíduos como seres transformadores (Freire, 1983).

Por muitos anos houve um cenário histórico de submissão, diminuição e rebaixamento intelectual e social sofrido pelos trabalhadores rurais, que foram reféns de um sistema cujas únicas vozes ouvidas eram aquelas dos grandes latifundiários 
(Freire, 1983). Esse mesmo autor conclui sua obra propondo aos extensionistas uma abordagem de trabalho com consciência mais humanista:

"Humanismo que, recusando tanto o desespero quanto o otimismo ingênuo, é, por isto, esperançosamente crítico. E sua esperança crítica repousa numa crença também crítica: a crença em que os homens podem fazer e refazer as coisas; podem transformar o mundo [...]" (Freire, 1983, p.91,).

Nos anos 1990, o Governo Collor acabou por dissolver a EMBRATER, pois se acreditava que a promessa de modernização do campo, que motivou a criação dessa estatal, não justificava mais a sua existência, tendo em vista que a agricultura brasileira já estava em pleno vôo e se mostrava independente. Era um momento de hiperinflação e tentativa de estabilização da economia, assim, Fernando Collor foi eleito em um contexto de abertura de mercado sob a égide do neoliberalismo, que fora traduzida como uma reforma de Estado com corte de funcionários, redução dos salários reais e diminuição "do inchaço da máquina pública" (Bresser-Pereira, 2003). Os governos estaduais que entenderam como importante a manutenção das agências de ATER foram assim sobrevivendo, sem apoio do Governo Federal. Segundo Gonçalves et al. (2016), inicia-se nova discussão do chamado terceiro setor (composto por organizações não governamentais - ONGs, sindicatos e associações) que entrava em crise, já que as agências internacionais mudaram suas prioridades de financiamento e voltaram seus esforços para o Leste Europeu e para o Terceiro Mundo, com renda per capita inferior à brasileira. Ainda sobre esse período, afirma Gonçalves et al. (2016, p. 91):

“[...] o Movimento dos Trabalhadores Rurais sem Terra (MST) e a Confederação Nacional dos Trabalhadores na Agricultura (Contag) desenvolveram ações que legitimaram politicamente estudos acadêmicos os quais propunham uma nova categoria de análise: a agricultura familiar. Esse conceito influenciaria as políticas públicas dos anos 90 (restantes), com a intensificação de ações sobre a reforma agrária e o fortalecimento da categoria de produtor rural familiar." (Gonçalves et al., 2016).

Ainda cabe destaque nesta década a criação do Programa Nacional para a Agricultura Familiar (PRONAF), durante o Governo Itamar Franco, em 1996, uma política de crédito rural específica para determinado nicho, a agricultura familiar, que pela primeira vez ganha nome enquanto categoria política. Com a criação desse programa, as disputas entre as ATERs e o terceiro setor pela verba destinada à agricultura familiar fez com que os movimentos sociais passassem a reivindicar a Ater pública, gratuita e de qualidade (Gonçalves et al., 2016). Vale citar ainda a criação do Ministério do Desenvolvimento Agrário (MDA), já no governo Fernando Henrique Cardoso, em 1999, que deteve como principal função, articular as ações voltadas à promoção da agricultura familiar, fazendo contraponto aos interesses assumidos pelo Ministério da Agricultura Pecuária e Abastecimento (MAPA).

A partir do PRONAF, outras políticas públicas foram criadas - cabendo destaque para o Programa Nacional de Alimentação Escolar (PNAE) e Programa de Aquisição de Alimentos (PAA), cujas implicações de atuação do profissional de Extensão Rural serão posteriormente discutidas na próxima seção - com o propósito de fortalecer a agricultura familiar. Mas quem eram os agricultores familiares? No Brasil, por força da Lei $\mathrm{n}^{\circ} 11.326$, sancionada apenas em 2006 , que em seu Art. $3^{\circ}$ diz:

“[...] agricultor familiar e empreendedor familiar rural é aquele que pratica atividades no meio rural, atendendo, simultaneamente, aos seguintes requisitos: I - não detenha, a qualquer título, área maior do que 4 (quatro) módulos fiscais; II - utilize predominantemente mão-de-obra da própria família nas atividades econômicas do seu estabelecimento ou empreendimento; III - tenha renda familiar predominantemente originada de atividades econômicas vinculadas ao próprio estabelecimento ou empreendimento; IV - dirija seu estabelecimento ou empreendimento com sua família.” (Lei no 11.326, 2006). 
Já para Wanderley (2009), a agricultura familiar pode ser definida como uma modalidade da agricultura em que a produção, a moradia, a atividade profissional, a economia doméstica, o patrimônio familiar e as relações de reprodução socioeconômica se combinam de modo indissociável.

Aos anos 2003, Caporal (2006) afirma que foi a partir das modificações ocorridas no cenário político, com a liderança do Presidente Luís Inácio Lula da Silva - que em campanha eleitoral afirmava compreender o Brasil como um país de bemestar social, com vistas à descentralização e participação popular - que propiciaram a criação de um documento, fruto de um processo democrático e participativo, envolvendo diversas entidades representativas, que organizadas construíram uma série de consensos e acordos em conjunto para originar o que se chamou de PNATER, Política Nacional de Assistência Técnica e Extensão Rural (Caporal, 2006).

Esses debates deram muita visibilidade ao trabalho do extensionista rural, que gradativamente veio construindo e desconstruindo sua atuação profissional, pois executava muito mais que serviços técnicos ou agronômicos, o extensionista vinha há anos desempenhando serviços sociais que ultrapassavam seu conhecimento acadêmico.

A princípio, a PNATER foi discutida e formulada para se tornar um documento orientador de uma Extensão Rural com vistas à promoção do desenvolvimento rural sustentável, que incentivava a potencialização do uso sustentável dos recursos naturais, que apoiava a adoção de uma abordagem multidisciplinar e interdisciplinar, com enfoque em metodologias participativas, e ainda utilizando princípios da Agroecologia - o primeiro texto assim dizia. Além de enfatizar processos educativos permanentes e continuados a partir de um enfoque dialético, humanista e construtivista (Caporal, 2006). A PNATER, por sua vez, propiciou a elaboração do Programa Nacional de Assistência Técnica e Extensão Rural (PRONATER) que teve sua primeira edição lançada em 2005. Sobre esse momento, Lusa (2013) afirma representar um avanço relevante da atenção à produtividade camponesa, pois institucionalizou a ATER como política pública específica, fundamentando a atenção dos agentes de ATER em diretrizes nacionais.

Entretanto, a condução das agendas de interesse não ocorrrem sem disputas, quando a Lei $\mathrm{n}^{\circ} 12.188$ (2010) ao ser sancionada, suprimiu-se do texto primário o direcionamento dado pelo termo Agroecologia, o que gerou alguns descontentamentos de entidades que participaram da elaboração da lei de ATER. Segundo o seu $3^{\circ}$ Art., diz-se que são princípios da PNATER:

"[...] desenvolvimento rural sustentável, compatível com a utilização adequada dos recursos naturais e com a preservação do meio ambiente; gratuidade, qualidade e acessibilidade aos serviços de assistência técnica e Extensão Rural; adoção de metodologia participativa, com enfoque multidisciplinar, interdisciplinar e intercultural, buscando a construção da cidadania e a democratização da gestão da política pública; adoção dos princípios da agricultura de base ecológica [grifo nosso] como enfoque preferencial para o desenvolvimento de sistemas de produção sustentáveis; equidade nas relações de gênero, geração, raça e etnia; e contribuição para a segurança e soberania alimentar e nutricional..” (Lei n $\left.{ }^{\circ} 12.188,2010\right)$.

A aprovação da Lei no 12.897 (2013), que institui a Agência Nacional de Assistência Técnica e Extensão Rural (ANATER), além de incluir as ações da Ater médios produtores no bojo de suas ações, o que retira a exclusividade da agricultura familiar, causou ainda mais indignação de grupos que se sentiram excluídos dos debates de regulamentação dos serviços de Ater:

“[...] fomos surpreendidos com o anúncio intempestivo da proposta de criação de uma Agência Nacional de ATER (ANATER), cuja formulação já se encontra no formato de um Projeto de Lei em estado avançado de debate no Congresso Nacional. A exposição de motivos que acompanha o referido PL não deixa dúvidas com relação à intenção do governo de reafirmar a perspectiva difusionista, ao atribuir centralidade do sistema de ATER à Embrapa [...] nos colocamos radicalmente contra o movimento em curso que sinaliza uma clara desconstrução dos acúmulos duramente 
conquistados nos últimos anos no campo da ATER pública para a agricultura familiar.” (Associação Brasileira de Agroecologia, 2013).

Alguns estudos apontam a incoerência da ANATER frente aos objetivos da PNATER, dentre eles Zarnott et al. (2015) que avaliam que além das atribuições burocráticas vinculadas a oferta do serviço como o credenciamento das entidades, a ANATER visa transferir tecnologia e inovação e tem por função monitorar e avaliar se os resultados nesse sentido foram alcançados. A lei da PNATER define que a assistência deve se tratar de um serviço de educação não formal, de caráter continuado, contudo pelo fato dos projetos aprovados em Chmadas Públicas terem de um a no máximo dois anos de previsão a contradição se apresenta na impossibilidade de garantir a continuidade dos serviços nessas condições, já que diante de um orçamento limitado, o cumprimento desse dispositivo se torna, na prática, inviável (Caporal, 2011). Com relação ao retorno da via tecnológica, com foco na transferência de tecnologia e resultados mensuráveis a curto prazo, Zarnott et al. (2015) denunciam o retorno ao típico período difusionista como orientação geral para o serviço de extensão rural.

De toda maneira, a PNATER trouxe avanços, sobretudo quando privilegia categorias, que desde a criação do PRONAF vieram paulatinamente conquistando espaço e mais visibilidade, sendo explicitamente citadas no corpo da lei, considerando-se como seus beneficiários (Lei $\left.{ }^{\circ} 12.188,2010\right)$ :

"I - Os assentados da reforma agrária, os povos indígenas, os remanescentes de quilombos e os demais povos e comunidades tradicionais; e II - nos termos da Lei $\mathrm{n}^{\circ}$ 11.326, de 24 de julho de 2006, os agricultores familiares ou empreendimentos familiares rurais, os silvicultores, aquicultores, extrativistas e pescadores, bem como os beneficiários de programas de colonização e irrigação enquadrados nos limites daquela Lei." (Lei no 12.188, 2010).

Nos anos que se seguiram, é importante salientar algumas mudanças importantes tais como a extinção do MDA, em 2016, durante o Governo Michel Temer, assim, todas as políticas que estavam ligadas a esse ministério, criadas com a intenção de promover a agricultura familiar, foram redistribuídas para o Ministério do Desenvolvimento Social (MDS). Este último, em seguida, foi extinto pela Medida Provisória $n^{\circ} 870$ (2019) do Governo Bolsonaro, que entregou suas pastas ao Ministério da Agricultura (Medida Provisória nº 870, 2019). Em 2020, com a crise sanitária mundial causada pela pandemia do Coronavírus, com número de óbitos que somavam 194.949 cidadãos até o fim do ano (dados oficiais do governo - Painel Coronavírus), o Brasil se viu impelido a se adaptar perante às novas condições necessárias para impedir novos contágios e continuar exercendo suas atividades profissionais, na medida do possível, remotamente. Assim, se viu por todas as categorias profissionais, incluindo os extensionistas, aprendendo novas formas de trabalho utilizando tecnologias da informação (celulares, computadores, tablets, etc...). Destarte, a administração pública e as formas de condução das agendas de interesse das categorias sociais aqui expostas, continuam exigindo atenção e esforço dos governantes. $\mathrm{O}$ extensionista rural permanece num esforço contínuo para se capacitar e atender às demandas dos agricultores familiares e médios produtores que buscam melhorias nas condições de produção e escoamento de seus produtos.

\subsection{Atribuições da Extensão Rural}

Conforme demonstrado no decurso desse trabalho, a Extensão Rural foi alvo de estudos de diversos pesquisadores ao longo dos anos, e ao apontar demandas e realizar diversas críticas em torno de suas ações e resultados, oferece-se oportunidade aos agentes de extensão de se aperfeiçoarem. É nesse sentido que acreditamos que a pesquisa promove uma constante melhoria dos serviços prestados por esses profissionais. Por esse motivo, concordamos com Lusa (2013) quando afirma que as discussões que tornaram a Extensão Rural um objeto de análise, colaboraram para situá-la na prática, orientando sua execução, e evidenciando seus limites, a partir do momento em que se aponta um horizonte diversificado de ideias às quais explorar. Desde seu nascedouro, as práticas de Extensão Rural no Brasil eram desempenhadas basicamente por engenheiros agrônomos, que ensinavam técnicas agrícolas aos trabalhadores rurais, e economistas domésticas que ensinavam técnicas de higienização 
de alimentos, dentre outras atividades, às mulheres do campo. Nesse primeiro momento, entendia-se o extensionista como um comunicador ou educador com o papel de persuadir e divulgar, ou seja, repassar as soluções tecnológicas "convencendo" o agricultor a empregá-las no campo.

Franco et al. (2019) ressaltam que:

"Cabe ao extensionista, em essência, o papel de indutor/difusor de inovações tecnológicas, além de elaborador de projetos de crédito rural. A tecnologia é concebida como o foco principal do processo de intervenção e único meio imaginado para aumentar a produção e produtividade tanto da terra, quanto do trabalho.” (Franco et al., 2019).

Após os debates que se seguiram dos anos 80 em diante, esse papel de comunicador e educador, aos poucos foi sendo substituído pela alcunha de mediador. Kreutz et al. (2005) afirmam que grande parcela dos extensionistas assumem-se como moderadores, sensibilizadores, animadores, facilitadores, entre outras denominações, para em última instância, repassar seus conhecimentos com, não raras vezes, a desqualificação do conhecimento popular. Já para Franco et al. (2019), nesse momento a Extensão Rural:

"Segue uma orientação pedagógica dialógica e problematizadora, com foco nos agricultores deixados de lado pelo processo seletivo de modernização. Admite o extensionista como um catalisador de processos sociais, além de agente de promoção do desenvolvimento. A tecnologia, por sua vez, é considerada essencial, mas complementar ao processo de promoção do desenvolvimento, devendo ser local e socialmente adequada.” (Franco et al., 2019).

Conforme exposto na seção anterior, a promulgação do PRONAF foi uma porta aberta para outras políticas de ação complementares ao fomento dos agricultores familiares, que a exemplo do PAA e do PNAE, se apresentam como políticas que combinam a promoção da segurança alimentar, combatendo a fome de pessoas em vulnerabilidade social e ampliando o mercado de comercialização dos produtos oriundos da produção familiar. Estas políticas também trouxeram uma série de desafios aos agentes de extensão, sobretudo no momento da implementação. Silva e Melo (2000) afirmam que programas elaborados por formuladores de políticas públicas delimitam apenas um conjunto limitado de cursos de ações e decisões que os agentes devem tomar, o que confere um amplo espaço discricionário de atuação dos agentes implementadores. Por ser continuamente qualificado de forma negativa pelo excesso de burocracias, esse espaço é onde predominam as práticas inovadoras e criativas. (Silva \& Melo, 2000). Para Lima e Oliveira (2020), esse espaço é preenchido por "burocratas de nível de rua", um conceito defendido por Michael Lipsky, que em um contexto de elevado grau de discricionaridade e relativa autonomia, diz-se que suas decisões, rotinas e dispositivos criados diante da atuação em seu trabalho fundem-se às políticas públicas que implementam (Lima \& Oliveira, 2020).

Para compreender esse conceito, Lipsky (2019) explica que burocratas de nível de rua podem ser assim qualificados quando trabalhadores do serviço público interagem diretamente com os cidadãos durante o exercício de seus trabalhos e possuem substancial autonomia para a execução de políticas públicas. Podem ser professores, policiais, assistentes sociais, trabalhadores da área da saúde e muitos outros funcionários públicos que concedem o acesso a programas governamentais e possibilitam a prestação de serviços dentro destes programas, onde podemos incluir os agentes de extensão rural. Segundo esse mesmo autor, eles estão constantemente divididos entre: as demandas dos destinatários dos serviços - no caso os planejadores ou formuladores de políticas públicas - que querem maior efetividade e responsividade, e as demandas de cidadãos - os agricultores familiares - que querem mais eficiência e eficácia dos serviços públicos.

"Os burocratas de nível de rua dominam as controvérsias políticas sobre serviços públicos por duas razões. Primeiro, os debates sobre o escopo adequado e o foco dos serviços públicos são, essencialmente, debates sobre o escopo e a função desses funcionários públicos. Em segundo lugar, os burocratas de nível de rua têm um impacto considerável na vida das pessoas. Esse impacto pode ser de vários tipos. Eles introduzem ao cidadão as possíveis expectativas a respeito de serviços públicos e seu lugar na comunidade política. Eles determinam a elegibilidade dos cidadãos a respeito de benefícios e sanções governamentais. Eles supervisionam o tratamento (o serviço) que os cidadãos 
recebem nesses programas. Assim, os burocratas no nível de rua, implicitamente, mediam a relação constitucional entre cidadãos e o Estado. Em suma, eles detêm as chaves para uma dimensão de cidadania.” (Lipsky, p.39, 2019).

Com o surgimento da PNATER, a implementação de suas diretrizes determinarou um novo comportamento, e por conseguinte uma readapatação dos agentes de extensão, pois já no seu Art.4 $4^{\circ}$ explicita seus objetivos $\left(\right.$ Lei $\left.^{\circ}{ }^{\circ} 12.188,2010\right)$ :

"I - promover o desenvolvimento rural sustentável; II - apoiar iniciativas econômicas que promovam as potencialidades e vocações regionais e locais; III - aumentar a produção, a qualidade e a produtividade das atividades e serviços agropecuários e não agropecuários, inclusive agroextrativistas, florestais e artesanais; IV - promover a melhoria da qualidade de vida de seus beneficiários; V - assessorar as diversas fases das atividades econômicas, a gestão de negócios, sua organização, a produção, inserção no mercado e abastecimento, observando as peculiaridades das diferentes cadeias produtivas; VI - desenvolver ações voltadas ao uso, manejo, proteção, conservação e recuperação dos recursos naturais, dos agroecossistemas e da biodiversidade; VII - construir sistemas de produção sustentáveis a partir do conhecimento científico, empírico e tradicional; VIII - aumentar a renda do público beneficiário e agregar valor a sua produção; IX - apoiar o associativismo e o cooperativismo, bem como a formação de agentes de assistência técnica e extensão rural; X - promover o desenvolvimento e a apropriação de inovações tecnológicas e organizativas adequadas ao público beneficiário e a integração deste ao mercado produtivo nacional; XI - promover a integração da Ater com a pesquisa, aproximando a produção agrícola e o meio rural do conhecimento científico; e XII - contribuir para a expansão do aprendizado e da qualificação profissional e diversificada, apropriada e contextualizada à realidade do meio rural brasileiro." (Lei nº 12.188, 2010).

Esse norte proporcionado pela PNATER representou um conjunto de novas habilidades colocadas para o extensionista à luz do desenvolvimento rural sustentável com vistas à promoção de uma categoria social, a agricultura familiar, cujas demandas procuram-se corresponder. Neste sentido, cabe à Extensão Rural se aperfeiçoar, ou captar novos conhecimentos, para desempenhar atribuições de facilitador, educador, e mediador de processos de desenvolvimento rural (MDA, 2012).

Quando a PNATER apresentou como princípio norteador o uso de metodologias participativas, podemos recorrer ao alerta de Simões (2004) que advertiu que a participação não significa fazer as pessoas falarem para legitimar aquilo que lhes foi proposto por agentes de desenvolvimento. Demonstrando que o simples uso de metodologias em si não assegura a participação dos agricultores e das suas famílias. Kreutz et al. (2005) afirmam o seguinte sobre as famílias que demandam serviços de Extensão Rural:

"Elas precisam ser acompanhadas de um processo que impõe uma ruptura com as condutas que tendem a reproduzir as práticas tradicionais de dominação. Requer também uma ruptura com a perspectiva funcionalista da profissão, para dar lugar à valorização das experiências dos agricultores, como parte integrante do processo de produção do conhecimento." (Kreutz et al., p.53, 2005).

Considerando as metas de desenvolvimento, as novas regras, as funções e as estratégias de reforma propostas, os Sistemas de Extensão e Assessoria necessitam de novas competências e devem ter a faculdade de manejar uma série de atividades de inovações. Também devem possuir faculdades técnicas e funcionais para promover tecnologias agrícolas apropriadas, aplicar enfoques participativos, ajudar aos produtores a se organizar, a entender os mercados e as cadeias de valor e abordar as formas de variação de vulnerabilidade climática, social e econômica (Sulaiman \& Davis, 2012).

Mas o que vem a ser competência? O termo competência, pelo senso comum, é invariavelmente utilizado para designar uma pessoa que tem aptidão para realizar determinada tarefa. Segundo Fleury e Fleury (2001), o oposto, incompetência, não implica apenas negar uma capacidade, mas detém um sentimento pejorativo, depreciativo.

A competência, segundo McClelland e Spencer (apud Fleury \& Fleury, 2001), é uma característica subjacente a uma pessoa que é casualmente relacionada com desempenho superior na realização de uma tarefa ou em determinada situação. Diferenciavam ainda três tipos distintos de competência: aptidões - talento natural da pessoa, o qual pode vir a ser aprimorado; habilidades - demonstração de um talento particular na prática; e conhecimentos - aquilo que se entende que as pessoas 
precisam saber para desempenhar uma tarefa. O desenvolvimento de capacidades para satisfazer determinado fim pode ser estimulado, orientado, incrementado, com a intenção de obter determinadas competências.

Segundo Sulaiman e Davis (2012), organizações como a FAO vem propondo estratégias de desenvolvimento de capacidades funcionais e técnicas em três níveis: dos indivíduos, das organizações e do entorno. Pontualmente no nível dos indivíduos, ao qual se pretende focar neste artigo, estes mesmos autores resumem as capacidades requeridas em Sistemas de Extensão conforme o quadro que se segue:

Tabela 1. Capacidades de extensão requeridas em nível individual.

\begin{tabular}{|c|c|}
\hline Técnicas & Funções \\
\hline $\begin{array}{l}\text { Bom entendimento acerca de novas tecnologias, } \\
\text { práticas, normas, regulações e políticas } \\
\text { apropriadas, relevantes para o manejo da } \\
\text { agricultura e dos recursos naturais. } \\
\text { Algumas destas áreas técnicas incluem: } \\
\text { - opções técnicas para apoiar na adaptação às } \\
\text { mudanças climáticas; } \\
\text { agroindústria, valor agregado e desen- } \\
\text { volvimento de cadeias de valor; }\end{array}$ & $\begin{array}{l}\text { - Mobilização da comunidade (organizar os produtores e as mulheres da área } \\
\text { rural em diferentes tipos de grupos de interesses / atividades); } \\
\text { - } \quad \text { Desenvolvimento de organizações de agricultores (organizar, apoiar e } \\
\text { legitimar as organizações de agricultores para que assumam novas tarefas de } \\
\text { extensão e de serviços de assessoria agrícola vinculá-las a novas fontes de } \\
\text { conhecimento e de serviços); } \\
\text { - } \quad \text { Facilitação (facilitar debates, o que permite a criação de consensos e ações } \\
\text { conjuntas, acompanhamento dos processos das diferentes partes interessadas); } \\
\text { - } \quad \text { Treinamento (autorreflexão dirigida e assessoria de especialistas para } \\
\text { atingir aperfeiçoamento); } \\
\text { - } \quad \text { Aprendizagem reflexiva (organizar oficinas de intercâmbio de experiências } \\
\text { e facilitar a aprendizagem); } \\
\text { - } \quad \text { Mediação dos conflitos (melhorar o diálogo e ajudar a chegar a um acordo); } \\
\text { - } \quad \text { Negociação (ajudar a alcançar um compromisso satisfatório ou acordo entre } \\
\text { pessoas ou grupos e desenvolver a capacidade de negociação entre outros } \\
\text { interessados); } \\
\text { - } \quad \text { Intermediação (a criação de relações entre uma ampla gama de atores); } \\
\text { - } \quad \text { Desenvolvimento de redes e associações; } \\
\text { - } \quad \text { Propor mudanças nas políticas e instituições; } \\
\text { - Capacidade de liderança para inspirar e motivar; } \\
\text { - } \quad \text { Manejo de recursos (humanos e financeiros); } \\
\text { - Pensamento crítico; } \\
\text { - } \quad \text { Resolução de problemas; } \\
\text { - } \quad \text { Autorreflexão/crítica e aprendizagem com base nos erros; } \\
\text { - } \quad \text { Mentalidade de serviço; } \\
\text { - } \quad \text { Prestação de contas; } \\
\text { - Responsabilhar ed com equipes multi-organizacionais e multisetoriais; } \\
\quad \text { mulheres da área rural e usar enfoques de extensão sensíveis } \\
\text { - }\end{array}$ \\
\hline
\end{tabular}

Nota: Fonte: Traduzido e adaptado pelos autores com base em: "El "Nuevo Extensionista": Roles, Estrategias y Capacidades para Fortalecer los Servicios de Extensión y Asesoría,” de Sulaiman V, R. \& Davis, K. (2012, p.8).

Conforme a própria afirmação de Sulaiman e Davis (2012), todos os componentes desta longa lista de habilidades citadas na Tabela 1 jamais se encontrarão em um único indivíduo, nem mesmo em uma só organização. E é por este motivo 
que Sulaiman e Davis (2012) afirmam que o desenvolvimento de capacidades a nível individual deve ser organizado de forma a combinar especialistas com diferentes antecedentes, com experiências em diferentes aspectos: de produção, empresas e mercados, de construção de capital social, de manejo de relações, de apoio a políticas, de desenvolvimento de capacidades, de solução de problemas e vínculos com organizações pares e de maior hierarquia.

\section{Considerações Finais}

Diante da indagação inicial sobre qual é a gama de habilidades e atribuições em diferentes contextos, este artigo lançou luz sobre a trajetória histórica da Extensão Rural e suas implicações no comportamento dos agentes extensionistas, buscou compreender as demandas institucionalizadas no exercício de suas funções e apresentou as multifuncionalidades inerentes à profissão de extensionista rural.

Sobre essa temática, a escolha metodológica por um artigo de revisão bibliográfica, não permitiram responder, por outro lado: como o extensionista rural tem enfrentado os desafios frente às diferentes demandas que ora referencia-se no modelo clássico difusionista, ora no modelo humanista construtivista? E ainda, cabe questionar quais são os mecanismos de aprendizagem e adaptação acionados para seguir a rota dessas transformações? No caso do profissional de extensão rural, enquanto agente de implementação de políticas públicas, a teoria que define "burocratas de nível de rua" permitiu vislumbrar a importância de sua atuação na interação com os agricultores familiares na execução de programas governamentais. Contudo, as questões relativas a compreesão do "como" esses agentes de implementação realizam tais práticas, "o que" as influência e suas "consequências" é um tema relevante e poucos estudos foram até o momento publicados no que tange às ações dos agentes de extensão rural. Tais perguntas carecem de um estudo empírico aprofundado, considerando a diversidade da atuação extensionista nos diferentes contextos regionais do Brasil.

Ainda que os profissionais de Extensão Rural se orientassem apenas pelas normativas que se colocam frente à realidade do campo em um Brasil tão diversificado e dinâmico, não seria possível exigir tamanha multifuncionalidade deste profissional. É evidente que não se pode solicitar de um único profissional tamanho espectro de competências, pois a tarefa de desenvolvimento rural requer investimentos contínuos, tanto públicos quanto privados, e como a própria PNATER aponta, a multifuncionalidade é inerente à formação de equipes multidisciplinares. Essa condição parece o caminho mais racional frente às demandas que se pretende transpor, uma vez que a contribuição de um agente extensionista pode ser complementada pela formação do outro. Ainda mais relevante foram as transformações ocorridas durante a crise sanitária mundial gerada pelo vírus do Covid-19, que exigiu de muitos profissionais uma adaptação ao trabalho remoto, e que certamente exigiu das agências de ATER e de seus agentes. Uma ATER remota faz emergir um novo portfólio de competências, sendo mister que estudos futuros também abordem avaliações sobre essas competências.

\section{Referências}

Associação Brasileira de Agroecologia - ABA. (2013). Moção de repúdio ao processo de criação e concepção da ANATER. III Encontro Internacional de Agroecologia. http://www.eiabotucatu2013.blogspot.com.br/p/mocao-de-repudioao-processo-de.html.

Axinn, G. (1988). Guide on Alternative Extension Approaches. Rome: FAO.

Bresser-Pereira, L. C. (2003). Desenvolvimento e crise no Brasil: história, economia e política de Getúlio Vargas a Lula: Editora 34.

Caporal, F. R.(2011). Lei de Ater: exclusão da Agroecologia e outras armadilhas. Cadernos de Agroecologia, 6(2), dez/2011.

Caporal, F. R. (2006). Política Nacional de Ater: primeiros passos de sua implementação e alguns obstáculos e desafios a serem enfrentados. In: Tavares, J.R.; Ramos, L. (Org.). Assistência técnica e extensão rural: construindo o conhecimento agroecológico. Manaus: Instituto de Desenvolvimento Agropecuário do Amazonas - IDAM, p.9-34.

Carnwell, R., \& Daly, W. (2001). Strategies for the construction of a critical review of the literature. Nurse Educ Pract 1: 57-63. https://www.sciencedirect.com/science/article/abs/pii/S1471595301900083?via\%3Dihub. 
Domit, L. A., Lima, D., Adegas, F. S., Dalbosco, M., Gomes, C., Oliveira, A. B., \& Campanini, S. M. S. (2007). Manual de implantação do treino e visita $(T \& V)$. Ed. Embrapa. Londrina. 86 p.

Fleury, M. T. L., \& Fleury, A. (2001). Construindo o conceito de competência. Revista De Administração Contemporânea, 5(spe), 183-196. https://doi.org/10.1590/S1415-65552001000500010.

Fonseca, M. T. L. (1985). Extensão Rural: uma educação para o capital. Edições Loyola, São Paulo.

Franco, M. H. M., Romarco, M. L., Borges, T. L., \& Gomes, M. C. (2019). O discurso institucional das entidades públicas de ATER. DRd - Desenvolvimento Regional Em Debate, 9, 263-283.

Freire, P. (1983) Extensão ou Comunicação: Paz e terra.

Gonçalves, L. C., Ramirez, M. A., \& Santos, D. dos. (2016) Extensão Rural e conexões: FEPMVZ. 164 p.

Jornal Folha de São Paulo. (1986). 77 MILHÕES passam fome - Sarney recebe do sociólogo Hélio Jaguaribe um plano para combater a miséria no país. São Paulo, publicado em 9 de abril de 1986. Acervo online. http://almanaque.folha.uol.com.br/brasil_09abr1986.htm\#: :tex $\mathrm{t}=\mathrm{São} \% 20$ trezentas\%20páginas \%20datilografadas\%2C\%20onde,segundo\%20o\%20relatório\%20\%20é\%20prioritária.\&text=Pelo\%20Censo\%20de\%201980\% 2C\%20a,conforme $\% 20$ levant amentos\%20efetuados\%20pelo\%20IBGE.

Kreutz, I. J., Pinheiro, L. G., \& Cazella, S. A. A. (2005). A construção de novas atribuições para a assistência técnica e Extensão Rural: a mediação com reconhecimento da identidade. Revista Extensão Rural, DEAER/CPGExR - UFSM, Ano XII, Jan - Dez de 2005.

Lazzari, F. M., \& Souza, A. S. (2017). Revolução Verde: Impactos sobre os conhecimentos tradicionais. $4^{o}$ Congresso Internacional de Direito $e$ Contemporaneidade. Santa Maria - RS.

Lei $n^{o}$ 11.326, de 24 de julho de 2006.(2006). Lei da Agricultura Familiar. Estabelece as diretrizes para a formulação da Política Nacional da Agricultura Familiar e Empreendimentos Familiares Rurais. Portal da Câmara dos Deputados. https://www2.camara.leg.br/legin/fed/lei/2006/lei-11326-24-julho-2006544830-norma-pl.html

Lei $n^{\circ} 12.188$, de 11 de janeiro de 2010. (2010). Institui a política nacional de assistência técnica e Extensão Rural para a agricultura familiar e reforma agrária - PNATER e o programa nacional de assistência técnica e Extensão Rural na agricultura familiar e na reforma agrária - PRONATER, altera a Lei no 8.666, de 21 de junho de 1993, e dá outras providências. Diário Oficial da República Federativa do Brasil, Brasília, DF, 11 jan. 2010a. http:// www.planalto.gov.br/ccivil_03/_ato2007-2010/2010/lei/112188.htm.

Lei $n^{\circ}$ 12.897, de 18 de dezembro de 2013. (2013). Autoriza o Poder Executivo Federal a instituir serviço social autônomo denominado Agência Nacional de Assistência Técnica e Extensão Rural - ANATER e dá outras providências. Portal da Câmara dos Deputados. https://www2.camara.leg.br/legin/fed/lei/2013/lei-12897-18-dezembro-2013-777703-norma-pl.html

Lima, T. L. B., \& Oliveira, M. L. R. de. (2020). Implementação do Mercado Institucional do Programa Nacional de Alimentação Escolar em Patos de MinasMG. Desenvolvimento Em Questão, 18(52), 159-177.

Lipsky, M. (2019). Burocracia de nível de rua: dilemas do indivíduo nos serviços públicos. Brasília: Editora ENAP-Escola Nacional de Administração Pública.

Lusa, M. G. (2013). Política nacional de assistência técnica e Extensão Rural e serviço social: o campo como desafio. Cadernos Ceru 24(1), 06-2013.

Maniglia, E. (2009). As interfaces do direito agrário e dos direitos humanos e a segurança alimentar: Editora UNESP; São Paulo: Cultura Acadêmica. 277 p.

Medida Provisória $n^{o} 870$ de 2019. (2019). Estabelece a organização básica dos órgãos da Presidência da República e dos Ministérios, definindo suas competências e sua estrutura básica. https://www.camara.leg.br/proposicoesWeb/fichadetramitacao?idProposicao=2190288.

Ministério do Desenvolvimento Agrário - MDA (2012). $1^{a}$ Conferência Nacional sobre Assistência Técnica e Extensão Rural: Ater para a agricultura familiar e reforma agrária e o desenvolvimento sustentável do Brasil rural. Documento-base, Versão Nacional. http://www.mda.gov.br/sitemda/sites/sitemda/files/user_img_1068/Documento\%20Base\%201\%C2\%AA\%20CNATER\%2020Vers\%C3\%A3o\%20Nacional.p df.

Peixoto, M. (2008). Extensão Rural no Brasil - uma abordagem histórica da legislação. Textos para discussão 48. Consultoria Legislativa do Senado Federal - Coordenação de Estudos. Brasília.

Olinger, G. (2020). Aspectos históricos da Extensão Rural no Brasil e em Santa Catarina. Florianópolis, SC: Epagri, 2020. 84p. (Epagri Documentos, 306).

Ramos, C. L. F., \& Caporal, F. R. (2011). Contribuição da Educação a Distância para a formação de Extensionista Rural Agroecológico. Resumos do VII Congresso Brasileiro de Agroecologia - Fortaleza.

Rocha Junior, C. J. G., \& Cabral, R. M. (2016). O processo de transição de empreendimentos rurais tradicionais para as agroindústrias associativas no estado de Pernambuco: desafios para construir competências empreendedoras. Gestão \& Regionalidade (Online), 32, 68/94-83, 2016. https://seer.uscs.edu.br/index.php/revista_gestao/ar ticle/view/3156.

Rother, E. T. (2007). Revisão sistemática X revisão narrativa. Acta Paulista de Enfermagem, São Paulo, 20(2), p.v-vi, Junho 2007. http://www.scielo.br/scielo.php?script=sci_arttext\&pid=S0103-21002007000200001\&lng= en\&nrm=iso.

Sabato, J., \& Mackenzie, M. (1981). Tecnologia e Estrutura Produtiva. São Paulo, IPT Publicações, (10), 1981.

Silva, P. L. B., \& Melo, M. A. B. de. (2000). O processo de implementação de políticas públicas no Brasil: características e determinantes da avaliação de programas e projetos. Caderno NEPP/UNICAMP, Campinas, (48), 1-16. https://governancaegestao.files. wordpress.com/2008/05/teresa-aula_22.pdf 
Research, Society and Development, v. 10, n.6, e51110615503, 2021

(CC BY 4.0) | ISSN 2525-3409 | DOI: http://dx.doi.org/10.33448/rsd-v10i6.15503

Simões, A. (2004). Ensaio acerca da construção de novas competências para assistência técnica e Extensão Rural (ATER): do agente ao mediador de desenvolvimento. In: Encontro da Sociedade Brasileira de Sistemas de Produção, n.4, Aracaju.

Stavenhagen, R. (1985). Etnodesenvolvimento: Uma Dimensão Ignorada no Pensamento Desenvolvimentisto. Anuário Antropológico. (84). 11-44.

Sulaiman V, R. \& Davis, K. (2012). El "Nuevo Extensionista": Roles, Estrategias y Capacidades para Fortalecer los Servicios de Extensión y Asesoría. Global Forum for Rural Advisory Services - GFRAS, Lindau, Suiça.

Wanderley, M. N. B. (2009). O mundo rural como um espaço de vida: reflexões sobre a propriedade da terra, agricultura familiar e ruralidade. Série Estudos Rurais. Universidade Federal do Rio Grande do Sul - UFRGS. Porto Alegre:

Zarnott, A. V., Dalbianco, V. P., Neümann, P. S., \& Verardi, M. A. F. (2015). Avanços e retrocessos nas políticas de Extensão Rural: análise crítica sobre a ANATER. In: $53^{\circ}$ Congresso Brasileiro da SOBER - Sociedade Brasileira de Economia, Administração e Sociologia Rural. João Pessoa. 